Pacific Journal of Mathematics

SPLITTING OF GROUP REPRESENTATIONS 


\section{SPLITTING OF GROUP REPRESENTATIONS}

\section{R. Patrick Martineau}

Let $G$ be a finite group, and $V, W$ two modules over the group-ring $K G$, where $K$ is some field. In this note is described a method for proving that every $K G$-extension of $V$ by $W$ is a split extension. The method is applied to the groups $P S L\left(2,2^{\alpha}\right)$ when $K=G F\left(2^{\alpha}\right)$, giving in this case an alternative proof of a theorem of G. Higman.

1. The method. Fix the finite group $G$ and the field $K$. If $A$ is any left $K G$-module, we let $\operatorname{Cr}(G, A)$ denote the $K$-vector space of crossed homomorphisms from $G$ to $A$, that is,

$$
C r(G, A)=\{f: G \longrightarrow A / f(g h)=g f(h)+f(g), \text { all } g, h \in G\} .
$$

Suppose $G$ is generated by the elements $g_{1}, \cdots, g_{s}$ with relations $w_{1}, \cdots, w_{t}$. Here $w_{1}, \cdots, w_{t}$ are elements of the free group $F$, freely generated by $x_{1}, \cdots, x_{s}$, and we say that $g_{1}, \cdots, g_{s}$ satisfy the relation $w$ if $\alpha(w)=1$ where $\alpha$ is the homomorphism from $F$ to $G$ defined by $\alpha\left(x_{i}\right)=g_{i}, i=1, \cdots, s$.

We shall devise a criterion, in terms of $w_{1}, \cdots, w_{t}$, to decide whether or not a map from $G$ to $A$ is a crossed homomorphism. Let $\mathscr{C}$ be the set of maps $f:\left\{g_{1}, \cdots, g_{s}\right\} \rightarrow A$ which satisfy the following condition: for any $i \in\{1, \cdots, s\}$ for which $g_{i}^{-1} \in\left\{g_{1}, \cdots, g_{s}\right\}, f\left(g_{i}^{-1}\right)=$ $-g_{i}^{-1} f\left(g_{i}\right)$.

Now let $w \in F$ and $f \in \mathscr{C}$. We shall define, by induction on the length of $w$, an element $w^{*}(f)$ of $A$. If $w=1$, put $w^{*}(f)=0$. If $w=x_{k}^{\varepsilon}$ for some $\varepsilon= \pm 1$, then we define $w^{*}(f)=f\left(g_{k}^{\varepsilon}\right)$ if $g_{k}^{\varepsilon} \in\left\{g_{1}, \cdots, g_{s}\right\}$, and if $g_{k}^{\varepsilon} \notin\left\{g_{1}, \cdots, g_{s}\right\}$, we put $w^{*}(f)=-g_{k}^{-1} f\left(g_{k}\right)$. Finally, if $w=$ $v . x_{k}^{\varepsilon}$ for some $\varepsilon= \pm 1$, we define $w^{*}(f)=\alpha(v) \cdot f\left(g_{k}^{\varepsilon}\right)+v^{*}(f)$.

Notice that we do not need $w$ to be in reduced form, since according to the definition,

$$
\begin{aligned}
\left(w x_{i} x_{i}^{-1}\right)^{*}(f) & =\alpha(w) \cdot g_{i} f\left(g_{i}^{-1}\right)+\alpha(w) f\left(g_{i}\right)+w^{*}(f) \\
& =\alpha(w) g_{i}\left[f\left(g_{i}^{-1}\right)+g_{i}^{-1} f\left(g_{i}\right)\right]+w^{*}(f) \\
& =w^{*}(f),
\end{aligned}
$$

and similarly for $w x_{i}^{-1} x_{i}$.

[As an example, if $w=x_{1} x_{2}^{2}$, then $w^{*}(f)=g_{1} g_{2} f\left(g_{2}\right)+g_{1} f\left(g_{2}\right)+f\left(g_{1}\right)$.]

Lemma 1. If $v, w \in F$ and $f \in \mathscr{C}$, then

$$
(w v)^{*}(f)=\alpha(w) \cdot v^{*}(f)+w^{*}(f) \text {. }
$$


Proof. This is true by definition if $v=1$ or $v=x_{i}^{\varepsilon}, \varepsilon= \pm 1$. If we have $(w v)^{*}(f)=\alpha(w) \cdot v^{*}(f)+w^{*}(f)$ for two elements $w, v$ of $F$, and $\varepsilon= \pm 1$, then we have

$$
\begin{aligned}
\left(w v x_{i}^{\varepsilon}\right)^{*}(f) & =\alpha(w v) f\left(g_{i}^{\varepsilon}\right)+(w v)^{*}(f) \\
& =\alpha(w) \cdot \alpha(v) f\left(g_{i}^{\varepsilon}\right)+\alpha(w) v^{*}(f)+w^{*}(f) \\
& =\alpha(w)\left[\alpha(v) f\left(g_{i}^{\varepsilon}\right)+v^{*}(f)\right]+w^{*}(f) \\
& =\alpha(w)\left(v x_{i}^{\varepsilon}\right)^{*}(f)+w^{*}(f) .
\end{aligned}
$$

Thus the lemma holds by induction on the length of $v$.

Lemma 2. If $f \in C r(G, A)$, then

(i) $f \in \mathscr{C}$

(ii) if $w \in F$ then $w^{*}(f)=f(\alpha(w))$, and

(iii) for $i=1, \cdots, t, w_{i}^{*}(f)=0$.

Proof. If $f \in \operatorname{Cr}(G, A)$ then $f(1 \cdot 1)=1 \cdot f(1)+f(1)$, so $f(1)=0$. Then $0=f(1)=f\left(g_{i} \cdot g_{i}^{-1}\right)=g_{i} f\left(g_{i}^{-1}\right)+f\left(g_{i}\right)$, so that $f \in \mathscr{C}$.

The equation $w^{*}(f)=f(\alpha(w))$ holds if $w=1$ or $x_{i}$, by definition. If $w=x_{i}^{-1}$, then $w^{*}(f)=-g_{i}^{-1} f\left(g_{i}\right)=f\left(g_{i}^{-1}\right)$ since $f \in C r(G, A)$. If now $w=v x_{i}^{\varepsilon}, \varepsilon= \pm 1$, and $v^{*}(f)=f(\alpha(v))$, then

$$
\begin{aligned}
w^{*}(f) & =\alpha(v) f\left(g_{i}^{\varepsilon}\right)+v^{*}(f) \\
& =\alpha(v) f\left(g_{i}^{\varepsilon}\right)+f(\alpha(v)) \\
& =f\left(\alpha(v) \cdot g_{i}^{\varepsilon}\right) \quad \text { since } f \in C r(G, A) \\
& =f(\alpha(w)) .
\end{aligned}
$$

Thus (ii) holds by induction on the length of $w$. (iii) now follows immediately, since $\alpha\left(w_{i}\right)=1$ and $f(1)=0$.

We remark, though we shall not need this, that a converse of this result is also true, namely:

LEMma 3. If $w_{1}, \cdots, w_{t}$ are defining relations for $G$, and if $f \in \mathscr{C}$ satisfies $w_{i}^{*}(f)=0$ for $i=1, \cdots, t$, then $f$ can be extended (uniquely) to an element of $\operatorname{Cr}(G, A)$.

Proof. First of all we show that if $u \in \operatorname{ker} \alpha$, then $u^{*}(f)=0$. Now $\operatorname{ker} \alpha=\left\langle w_{1}, \cdots, w_{t}\right\rangle^{F}$, that is, the subgroup of $F$ generated by all elements of the form $v^{-1} w_{i} v, v \in F$. By definition, $1^{*}(f)=0$, so by Lemma $1, \alpha\left(v^{-1}\right) \cdot v^{*}(f)+\left(v^{-1}\right)^{*}(f)=0$. Again by Lemma 1 ,

$$
\begin{aligned}
\left(r^{-1} w_{i} v\right)^{*}(f) & =\alpha\left(v^{-1} w_{i}\right) \cdot v^{*}(f)+\left(v^{-1} w_{i}\right)^{*}(f) \\
& =\alpha\left(v^{-1}\right) \cdot \alpha\left(w_{i}\right) \cdot v^{*}(f)+\alpha\left(v^{-1}\right) w_{i}^{*}(f)+\left(v^{-1}\right)^{*}(f) .
\end{aligned}
$$

Since $\alpha\left(w_{i}\right)=1$ and $w_{i}^{*}(f)=0$, we have $\left(v^{-1} w_{i} v\right)^{*}(f)=0$. Finally by Lemma 1 , if $w^{*}(f)=0$ and $v^{*}(f)=0$ then $(w v)^{*}(f)=0$. Thus $u^{*}(f)=0$ for all $u \in \operatorname{ker} \alpha$. 
Now if $g$ is any element of $G$, then $g=\alpha(w)$ for some $w \in F$. Define $f(g)=w^{*}(f)$. Then this definition depends only on $g$, for if $g=\alpha(v)$ also, then $w v^{-1} \in \operatorname{ker} \alpha$, say $w v^{-1}=u$. But now $w=u v$, so by Lemma $1, w^{*}(f)=\alpha(u) \cdot v^{*}(f)+u^{*}(f)=v^{*}(f)$ since $\alpha(u)=1$ and $u^{*}(f)=0$.

Now if $g, h \in G$, say $g=\alpha(w), h=\alpha(v)$, then $f(g h)=(w v)^{*}(f)=$ $\alpha(w) v^{*}(f)+w^{*}(f)$ by Lemma 1 so $f(g h)=g f(h)+f(g)$, as required.

The uniqueness of $f$ is immediate from the fact that $f$ is already defined on a set of generators of $G$.

Lemmas 2(iii) and 3 tell us how to find $\operatorname{dim}_{K}(\operatorname{Cr}(G, A))$ : we look in $A$ for elements $a_{1}, \cdots, a_{s}$ satisfying the relations $w_{j}^{*}(f)=0$ which are necessary if $f$ is to be an element of $\operatorname{Cr}(G, A)$ with $f\left(g_{i}\right)=a_{i}, i=$ $1, \cdots, s$. The point of doing this is explained in the next result.

Let $V, W$ be two left $K G$-modules. The dual module $W^{*}$ is given the structure of a left $K G$-module by defining $\left(g w^{*}\right)(w)=w^{*}\left(g^{-1} w\right)$ for $g \in G, w^{*} \in W^{*}$ and $w \in W$. Then $V \otimes_{K} W^{*}=A$ is a left $K G$-module if we define $g\left(v \otimes w^{*}\right)=g v \otimes g w^{*}$. Let $C_{A}(G)$ denote $\{a \mid a \in A$ and $g a=a$ for all $g \in G\}$.

Lemma 4. If $\operatorname{dim}_{K}(C r(G, A)) \leqq \operatorname{dim}_{K}(A)-\operatorname{dim}_{K}\left(C_{A}(G)\right)$, then every $K G$-extension of $V$ by $W$ is a split extension.

Proof. By Theorem 10, page 235, of [2], there is a one-to-one correspondence between classes of equivalent $K G$-extensions of $V$ by $W$, and elements of $H^{1}(G, A)$, and by [2], page $231, H^{1}(G, A)$ is the quotient space $\operatorname{Cr}(G, A) / P$, where $P$ is the subspace of principal crossed homomorphisms, that is, $P=\{f: G \rightarrow A$ / for some $a \in A, f(g)=g a-a$ for all $g \in G\}$.

To prove Lemma 4, therefore, if suffices to show that $\operatorname{dim} P \geqq$ $\operatorname{dim}(\operatorname{Cr}(G, A))$, and so by the hypothesis, we need only prove $\operatorname{dim} P \geqq$ $\operatorname{dim} A-\operatorname{dim}\left(C_{A}(G)\right)$.

Let $\left\{a_{r+1}, \cdots, a_{n}\right\}$ be a basis for $C_{A}(G)$, and extend it to a basis $\left\{a_{1}, \cdots, a_{r}, a_{r+1}, \cdots, a_{n}\right\}$ for $A$. For $i=1, \cdots, r$ define $f_{i}(g)=g a_{i}-a_{i}$ for all $g \in G$, so that $f_{i} \in P$. If we have $\sum_{i=1}^{r} \alpha_{i} f_{i}=0$ with $\alpha_{i} \in K, i=$ $1, \cdots, r$, then for all $g \in G, \sum_{i=1}^{r} \alpha_{i}\left(g \alpha_{i}-\alpha_{i}\right)=0$, so that for all $g \in G, \sum_{i=1}^{r} \alpha_{i} a_{i}=g\left(\sum_{i=1}^{r} \alpha_{i} a_{i}\right)$.

Thus $\sum_{i=1}^{r} \alpha_{i} a_{i} \in C_{A}(G)$, so $\alpha_{i}=0$ for $i=1, \cdots, r$. Hence $f_{1}, \cdots, f_{r}$ are linearly independent, and the Lemma is proved.

2. SL $\left(2,2^{n}\right)$. As an application we take $G=S L\left(2,2^{n}\right)$ and $K=$ $G F\left(2^{n}\right)$. Let $V=V_{0}$ be the 'natural' 2-dimensional representation of $G$ over $K$. Then $G$ is generated by elements $g_{1}, g_{2}, g_{3}$ whose action on $V_{0}$ can be represented by matrices $\left(\begin{array}{l}01 \\ 10\end{array}\right),\left(\begin{array}{l}10 \\ 11\end{array}\right),\left(\begin{array}{l}\theta 0 \\ 0 \theta^{-1}\end{array}\right)$, where $\theta$ is 
a primitive $\left(2^{n}-1\right)$ st root of 1 . A short calculation shows that $g_{1}, g_{2}$ and $g_{3}$ satisfy the relations

$$
\left\{\begin{array}{l}
w_{1}=\left(x_{1} x_{2}\right)^{3} w_{2}=\left(x_{1} x_{3}\right)^{2} \\
w_{3}=x_{1}^{2}, w_{4}=x_{2}^{2}, w_{5}=x_{3}^{k}, \quad \text { where } k=2^{n}-1 .
\end{array}\right.
$$

We take $W=\left(V_{i}\right)^{*}$, where $V_{i}$ is the (2-dimensional) representation of $G$ over $K$ obtained by applying the field automorphism $\beta \rightarrow \beta^{2^{i}}$ to the entries of the matrices above. (In fact, all 2-dimensional irreducible representations of $G$ over $K$ are of this form-see [1], Theorem 8.2). Thus $W^{*}$ has a basis with respect to which the matrices of $g_{1}, g_{2}, g_{3}$ are respectively $\left(\begin{array}{l}01 \\ 10\end{array}\right),\left(\begin{array}{l}10 \\ 11\end{array}\right)$ and $\left(\begin{array}{l}\psi 0 \\ 0 \psi^{-1}\end{array}\right)$, where $\psi=\theta^{2 i}$.

Let $A=V \otimes_{K} W^{*}$, take $f \in C r(G, A)$ and suppose $f\left(g_{i}\right)=a_{i}, i=$ 1, 2, 3. Then from $\left(^{*}\right)$ and Lemma 2(iii) we have

(1) $0=w_{1}^{*}(f)=\left(g_{1} g_{2} g_{1} g_{2}+g_{1} g_{2}+1\right) a_{1}+\left(g_{1} g_{2} g_{1} g_{2} g_{1}+g_{1} g_{2} g_{1}+g_{1}\right) a_{2}$

(2) $0=w_{2}^{*}(f)=\left(g_{1} g_{3}+1\right) a_{1}+\left(g_{1} g_{3} g_{1}+g_{1}\right) a_{3}$

(3) $0=w_{3}^{*}(f)=\left(g_{1}+1\right) a_{1}$

(4) $0=w_{4}^{*}(f)=\left(g_{2}+1\right) a_{2}$

(5) $0=w_{5}^{*}(f)=\left(g_{3}^{k-1}+g_{3}^{k-2}+\cdots+g_{3}+1\right) a_{3}$.

If we use the relations $\left(^{*}\right)$, and equations (3) and (4), equation

(1) can be re-written as

$$
\left(g_{2}+g_{1} g_{2}+1\right) a_{1}+\left(1+g_{2} g_{1}+g_{1}\right) a_{2}=0 .
$$

If we multiply equation (2) by $g_{1}$ and note that $g_{1}^{2}=1$ and $g_{1} a_{1}=a_{1}$ (equation (3)), then we obtain

$$
\left(g_{3}+1\right) a_{1}+\left(g_{3} g_{1}+1\right) a_{3}=0 .
$$

Let $\bar{g}_{1}, \bar{g}_{2}, \bar{g}_{3}$ be matrices representing $g_{1}, g_{2}, g_{3}$ respectively in $A$. Then it is straightforward to calculate that the rank of the matrix

$$
M=\left(\begin{array}{ccc}
\bar{g}_{2}+\bar{g}_{1} \bar{g}_{2}+1 & 1+\bar{g}_{2} \bar{g}_{1}+\bar{g}_{1} & 0 \\
\bar{g}_{3}+1 & 0 & \bar{g}_{3} \bar{g}_{1}+1 \\
\bar{g}_{1}+1 & 0 & 0 \\
0 & \bar{g}_{2}+1 & 0 \\
0 & 0 & \bar{h}
\end{array}\right)
$$

where $\bar{h}=\sum_{t=0}^{k-1} \bar{g}_{3}^{t}$, is 8 if $i \neq 0$ and 9 if $i=0$.

Secondly, it is easy to show that $C_{A}(G)=0$ if $i \neq 0$, and that $\operatorname{dim}_{K}\left(C_{A}(G)\right)=1$ if $i=0$. Thus in either case, $\operatorname{dim}_{K}(\operatorname{Cr}(G, A)) \leqq$ $3.4-\operatorname{rank}(M) \leqq \operatorname{dim}_{K} A-\operatorname{dim}_{K}\left(C_{A}(G)\right)$. Hence by Lemma 4 , for any $i$, any $K G$-extentions of $V$ by $W$ is a split extension. 


\section{REFERENCES}

1. G. Higman, Odd Characterisations of Finite Simple Groups, Lecture notes, University of Michigan, 1968.

2. D. G. Northcott, An Introduction to Homological Algebra, Cambridge University Press, 1962.

Received November 9, 1971.

Mathematical INSTitute

UNIVERSITY OF OXFORD

OXFORD OXI 3LB, ENGLAND 



\section{PACIFIC JOURNAL OF MATHEMATICS}

\section{EDITORS}

\author{
H. SAMELson \\ Stanford University \\ Stanford, California 94305 \\ C. R. HоввY \\ University of Washington \\ Seattle, Washington 98105
}

J. DugundJI

Department of Mathematics

University of Southern California

Los Angeles, California 90007

RICHARD ARENS

University of California

Los Angeles, California 90024

\section{ASSOCIATE EDITORS}
E. F. BeCKENBACH
B. H. NEUMANN
F. WOLF
K. YoshidA

\section{SUPPORTING INSTITUTIONS}

UNIVERSITY OF BRITISH COLUMBIA

CALIFORNIA INSTITUTE OF TECHNOLOGY

UNIVERSITY OF CALIFORNIA

MONTANA STATE UNIVERSITY

UNIVERSITY OF NEVADA

NEW MEXICO STATE UNIVERSITY

OREGON STATE UNIVERSITY

UNIVERSITY OF OREGON

OSAKA UNIVERSITY

\author{
UNIVERSITY OF SOUTHERN CALIFORNIA \\ STANFORD UNIVERSITY \\ UNIVERSITY OF TOKYO \\ UNIVERSITY OF UTAH \\ WASHINGTON STATE UNIVERSITY \\ UNIVERSITY OF WASHINGTON

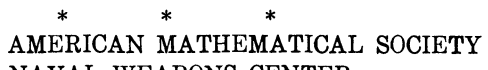 \\ NAVAL WEAPONS CENTER
}

The Supporting Institutions listed above contribute to the cost of publication of this Journal, but they are not owners or publishers and have no responsibility for its content or policies.

Mathematical papers intended for publication in the Pacific Journal of Mathematics should be in typed form or offset-reproduced, (not dittoed), double spaced with large margins. Underline Greek letters in red, German in green, and script in blue. The first paragraph or two must be capable of being used separately as a synopsis of the entire paper. The editorial "we" must not be used in the synopsis, and items of the bibliography should not be cited there unless absolutely necessary, in which case they must be identified by author and Journal, rather than by item number. Manuscripts, in duplicate if possible, may be sent to any one of the four editors. Please classify according to the scheme of Math. Rev. Index to Vol. 39. All other communications to the editors should be addressed to the managing editor, Richard Arens, University of California, Los Angeles, California, 90024.

50 reprints are provided free for each article; additional copies may be obtained at cost in multiples of 50 .

The Pacific Journal of Mathematics is issued monthly as of January 1966. Regular subscription rate: $\$ 48.00$ a year (6 Vols., 12 issues). Special rate: $\$ 24.00$ a year to individual members of supporting institutions.

Subscriptions, orders for back numbers, and changes of address should be sent to Pacific Journal of Mathematics, 103 Highland Boulevard, Berkeley, California, 94708.

PUBLISHED BY PACIFIC JOURNAL OF MATHEMATICS, A NON-PROFIT CORPORATION

Printed at Kokusai Bunken Insatsusha (International Academic Printing Co., Ltd.), 270, 3-chome Totsuka-cho, Shinjuku-ku, Tokyo 160, Japan. 


\section{Pacific Journal of Mathematics}

\section{Vol. 45, No. $2 \quad$ October, 1973}

Kenneth Paul Baclawski and Kenneth Kapp, Induced topologies for quasigroups and loops ............................................. 393

D. G. Bourgin, Fixed point and $\min -\max$ theorems $\ldots \ldots \ldots \ldots \ldots \ldots \ldots$

J. L. Brenner, Zolotarev's theorem on the Legendre symbol ............... 413

Jospeh Atkins Childress, Jr., Restricting isotopies of spheres .............. 415

John Edward Coury, Some results on lacunary Walsh series ................ 419

James B. Derr and N. P. Mukherjee, Generalized Sylow tower groups. II . . . . . . 427

Paul Frazier Duvall, Jr., Peter Fletcher and Robert Allen McCoy, Isotopy Galois

spaces .......................................... 435

Mary Rodriguez Embry, Strictly cyclic operator algebras on a Banach space ... 443

Abi (Abiadbollah) Fattahi, On generalizations of Sylow tower groups ......... 453

Burton I. Fein and Murray M. Schacher, Maximal subfields of tensor products . . 479

Ervin Fried and J. Sichler, Homomorphisms of commutative rings with unit

element .......................................... 485

Kenneth R. Goodearl, Essential products of nonsingular rings ............. 493

George Grätzer, Bjarni Jónsson and H. Lakser, The amalgamation property in

equational classes of modular lattices ...........................

507

$\mathrm{H}$. Groemer, On some mean values associated with a randomly selected simplex

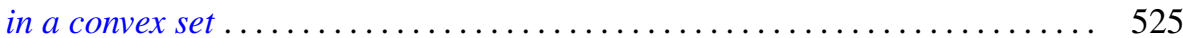

Marcel Herzog, Central 2-Sylow intersections .................... 535

Joel Saul Hillel, On the number of type-k translation-invariant groups ........ 539

Ronald Brian Kirk, A note on the Mackey topology for $\left(C^{b}(X)^{*}, C^{b}(X)\right) \ldots \ldots .543$

J. W. Lea, The peripherality of irreducible elements of lattice.............. 555

John Stewart Locker, Self-adjointness for multi-point differential operators ..... 561

Robert Patrick Martineau, Splitting of group representations ............... 571

Robert Massagli, On a new radical in a topological ring ................. 577

James Murdoch McPherson, Wild arcs in three-space. I. Families of Fox-Artin

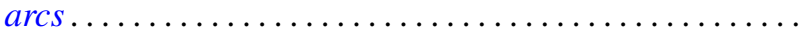

585

James Murdoch McPherson, Wild arcs in three-space. III. An invariant of

oriented local type for exceptional arcs . . . . . . . . . . . . ............ 599

Fred Richman, The constructive theory of countable abelian p-groups ........ 621

Edward Barry Saff and J. L. Walsh, On the convergence of rational functions

which interpolate in the roots of unity ..................

Harold Eugene Schlais, Non-aposyndesis and non-hereditary

decomposability..................................... 643

Mark Lawrence Teply, A class of divisible modules................... 653

Edward Joseph Tully, Jr., H-commutative semigroups in which each

homomorphism is uniquely determined by its kernel ................. 669

Garth William Warner, Jr., Zeta functions on the real general linear group ...... 681

Keith Yale, Cocyles with range $\{ \pm 1\} \ldots \ldots \ldots \ldots \ldots \ldots \ldots \ldots \ldots \ldots \ldots \ldots \ldots . \ldots \ldots$

Chi-Lin Yen, On the rest points of a nonlinear nonexpansive semigroup ........ 699 